\title{
A new biosensor detection system to overcome the Debye screening effect: dialysis-silicon nanowire field effect transistor
}

This article was published in the following Dove Press journal: International Journal of Nanomedicine

\author{
Hang Chen \\ Xiaoqian Zhao \\ Zhong Xi \\ Ye Zhang \\ Hang Li \\ Zengyao Li \\ Haoze Shi \\ Longchang Huang \\ Renhui Shen \\ Jianxin Tao \\ Tong Wang
}

Department of General Surgery, Nanjing Medical University Affiliated Wuxi

People's Hospital, Wuxi, Jiangsu Province, People's Republic of China
Correspondence: Tong Wang

Department of Department of General Surgery, Nanjing Medical University

Affiliated Wuxi People's Hospital, 299

Qingyang Road, Wuxi 214023, Jiangsu

Province, People's Republic of China

Tel +86 I30 I3675222

Email aanti@।63.com
Background: A silicon nanowire field effect transistor biosensor has four advantages in the detection of small biomolecules. It is mark-free, immediately responsive, highly sensitive, and specific. However, because of environments with a high salt concentration, the Debye screening effect has been a major issue in biological detection.

Objective: To overcome Debye screening effect, realize the clinical application of silicon nanowire field effect transistor and verify its specificity and sensitivity.

Materials and methods: The test solution was desalted by miniature blood dialyzer, and then the tumor markers were detected by silicon nanowire field effect transistor.

Results: Tumor markers in serum were detected successfully and their sensitivity and specificity were verified.

Conclusion: This method was found to effectively promote the development of semiconductor materials in biological solution detection.

Keywords: silicon nanowire, biosensor, Debye screening effect, tumor marker, dialysis

\section{Introduction}

Surgery is an effective treatment for early, midterm, and advanced tumors that have not undergone extensive metastasis. ${ }^{1,2}$ The five-year survival rate of patients who have undergone surgery was significantly higher than those without surgery. ${ }^{3,4}$ At present, the main diagnostic approach for early and middle stage malignant tumors include blood tumor markers, computed tomography (CT), magnetic resonance imaging (MRI), endoscopy, etc. ${ }^{5-8}$ Commonly used blood tumor marker protein detection methods include enzyme-linked immunosorbent assay (ELISA), gene chips, chemiluminescence, and multiple reaction monitoring (MRM), along with other methods. ${ }^{9,10}$ These methods have some limitations, such as a long detection time, marking, and a high detection concentration limit. ${ }^{11}$ When Cui et al first reported real-time protein detection using silicon nanowire devices, the application of silicon nanowire device detection technology developed interest within the research community. ${ }^{12}$

The detection principle of the silicon nanowire field effect transistor (SiNW-FET) biosensor is shown in Figure 2A. In brief, tumor markers are negatively charged particles in a weakly alkaline liquid, such as serum. These particles could be trapped by surfacefunctionalized silicon nanowires. This altered the carrier distribution in the silicon nanowire leading to changes in both current and conductance. ${ }^{13-16}$ This method is 


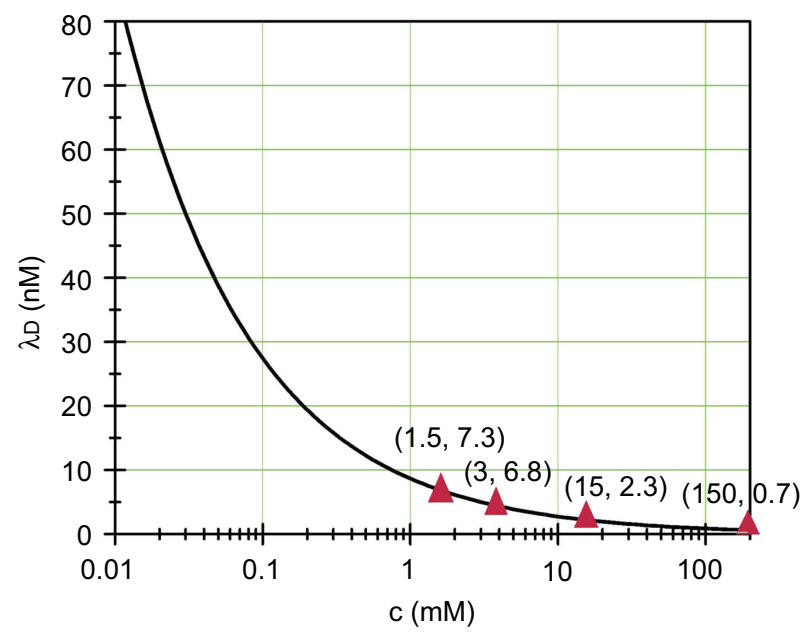

Figure I The relationship between debye length and ionic strength.

based on signal conversion, and the detection in biological and electrical signals was mark-free, immediately responsive, highly sensitive, and specific. ${ }^{17}$ Studies have demonstrated successful tumor marker detection in low-salt solutions (including CEA, AFP, and PSA). ${ }^{14,18,19}$ However, detection sensitivity in a high-salt concentration (such as whole blood and serum) was reduced or nonexistent due to interference from a high-salt concentration. ${ }^{20-22}$ Therefore, this detection method has not yet been applied in clinical practice. This interference was due to the Debye screening effect in semiconductor materials. $^{23}$ The Debye screening effect can be formulated in terms of the Debye length $\left(\lambda_{D}\right)$, which is calculated in the following manner: ${ }^{24,25}$

$$
\lambda_{\mathrm{D}}=\frac{\sqrt{\varepsilon \cdot k \cdot T}}{q} \cdot \frac{1}{\sqrt{\mathrm{C}}}
$$

$\varepsilon$ is the dielectric constant, $k$ is the Boltzmann constant, $T$ is the temperature, $q$ is the amount of electricity, and $\mathrm{c}$ is the ionic strength of the detection solution (where the typical human blood ionic strength is about $150 \mathrm{mM}$ ). $\lambda_{\mathrm{D}}$ is inversely proportional to the square root of the ionic strength (which is c) based on the Debye length formula (Figure 1). According to Figure 1, the Debye length in a normal physiological solution is about $0.7 \mathrm{~nm}$, which is much smaller than the size of certain protein molecules such as antigens and antibodies (about $10 \mathrm{~nm}$ in diameter). ${ }^{24,26}$ Therefore, the Debye screening effect remained to be solved for the detection of serum tumor markers.

Several solutions have been proposed to overcome the Debye screening effect, including (1) tailoring antibodies, ${ }^{27}$ (2) purifying serum tumor markers by an antigen-antibody binding reaction, ${ }^{28}$ (3) replacing antibodies functionalized on silicon nanowires with aptamers, ${ }^{24}$ (4) purifying serum with a microcentrifuge filter, ${ }^{14}$ (5) and adding a layer of biomolecule-permeable polymer on the semiconductor material to change the dielectric constant. ${ }^{29}$ All of these approaches increased the Debye length $\left(\lambda_{D}\right)$ or shortened the distance between the tumor marker antigen and the nanowire after binding with the antibody. Although the Debye screening effect can be partially overcome, the detection was still timeconsuming with relatively low specificity and sensitivity.

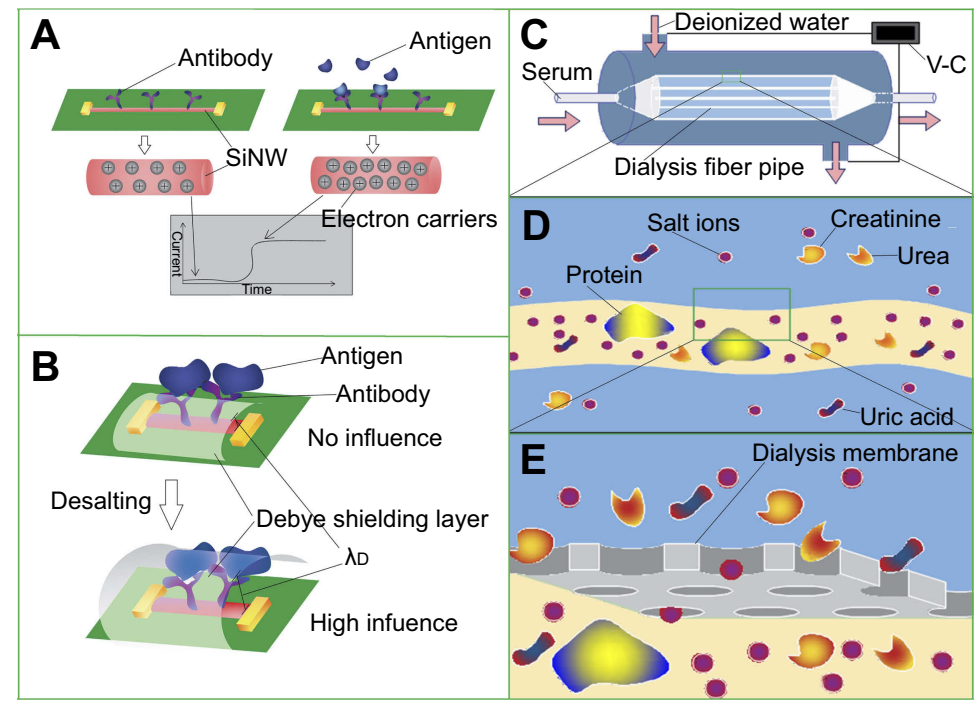

Figure 2 (A) The detection principle of SiNW-FET. (B) The principle of the Debye screening effect. (C-E) A schematic diagram of a miniature blood dialyzer. Abbreviation: SiNW-FET, silicon nanowire field effect transistor. 
This study proposed a method to solve the Debye screening effect for semiconductor biological detection by using a miniature blood dialyzer (as shown in Figure 2C-E) to desalinate serum, followed by detection with a SiNW-FET biosensor. The salt ions in the serum were filtered with a miniature blood dialyzer, while the tumor markers remained in the serum. ${ }^{30-32}$ As in the Debye length formula described above, the Debye length increased as the corresponding salt concentration decreased. Therefore, desalination effectively increased the Debye length, overcoming the Debye screening effect (as shown in Figure 2B). ${ }^{14,33}$ The process of salt removal by dialysis is simple and quick, and it gives an immediate response while retaining high sensitivity and specificity of the SiNW-FET biosensor. Thus, the miniature blood dialyzer provides a solution for semiconductor biological detection.

\section{Materials and methods}

Six-inch silicon-on-insulator (SOI) wafers (p-type (100) $\rho: 10-20 \Omega \mathrm{cm}$; buried oxidation layer: $120 \mathrm{~nm}$ ) were acquired from Nova Electronic Materials. Polydimethylsiloxane (PDMS) was purchased from Dow Corning Co. (Michigan, USA). 3-Aminopropyltriethoxysilane (APTES), glutaraldehyde (Glu), phosphate buffered saline (PBS; pH 7.4), AFP antigen and monoclonal antibody, CEA antigen and monoclonal antibody, bovine serum albumin (BSA) monoclonal antibody as well as green fluorescent protein (CD44) were obtained from Sigma-Aldrich (St Louis, MO, USA) Deionized water (DI; $\mathrm{R} \geq 18.2 \mathrm{M} \Omega \bullet \mathrm{cm}$ ) was produced with a Millipore system (Merck Millipore, Billerica, MA, USA). The serum was collected from 50 patients at Wuxi People's Hospital from 2016 to 2017. All participants provided written informed consent. The dialysis membrane was purchased from Fresenius Medical Care (Bad Homburg, Germany).

\section{Fabrication of silicon nanowire chips}

The p-type double gate nanodevices, which have been improved from the early single gate devices, were fabricated with a "top-down" approach, shown in Figure 3. The original material used for silicon nanowire devices was a 6-inch SOI wafer, which consisted of a $195 \mathrm{~nm}$ thick silicon layer, a $120 \mathrm{~nm} \mathrm{SiO}_{2}$ insulating layer, and a $600 \mu \mathrm{m}$ thick silicon substrate. ${ }^{18}$ First, the $195 \mathrm{~nm}$ thick silicon layer was oxidized for $7 \mathrm{hrs}$ to form a layer of $\mathrm{SiO}_{2}$ via dry-oxygen oxidation combined with a wet-oxygen oxidation mode. This was followed by etching the $\mathrm{SiO}_{2}$ with a buffered oxide etch (BOE) to thin the Si layer to $30 \mathrm{~nm}$. The nanowire pattern was formed by coating photolithography. Next, the reactive ion etching (RIE) method was adopted to etch the silicon outside the pattern and to wash the coating photoresist. A width of $500 \mathrm{~nm}$ and a height of $30 \mathrm{~nm}$ of silicon nanowire (SiNW) was built. The silicon dioxide layer, which was $50 \mathrm{~nm}$ thick, was plated over the nanowires via coating photolithography and Inductively Coupled Plasma Chemical Vapour Deposition (ICP CVD). Then, 3 electrodes (ie, a source electrode, a drain electrode, and a top gate electrode) made of $5 \mathrm{~nm}$ of titanium and $100 \mathrm{~nm}$ of gold were formed by means of coating photolithography and Physical Vapor Deposition (PVD). A SOI wafer was then turned over to form a layer composed of $5 \mathrm{~nm}$ of titanium and $100 \mathrm{~nm}$ of gold to the back electrode using PVD. This was followed by annealing at $300{ }^{\circ} \mathrm{C}$ in a vacuum to form favorable ohmic contacts. Finally, a layer of $100 \mathrm{~nm}$ of $\mathrm{SiO}_{2}$ and $160 \mathrm{~nm}$ of SiNx was plated on the surface of the device using Inductively Coupled Plasma Chemical Vapour Deposition (ICP CVD) in order to prevent a short circuit during detection. A section of SiNW about 10 microns long was left as the functional segment as shown in Figure 3.
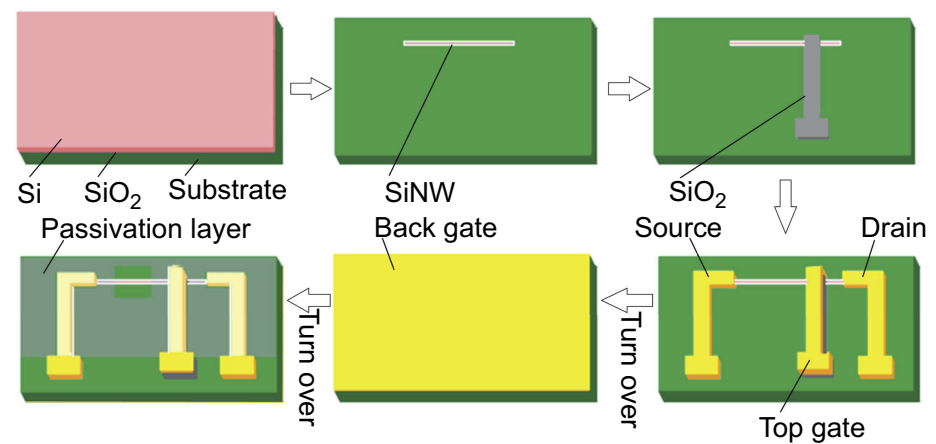

Figure 3 The fabrication process for silicon nanowire devices. Abbreviation: SiNW, silicon nanowire. 


\section{Surface functional antibody modifications}

The modification steps are shown in Figure 4. The chip was cleaned multiple times with DI water and its surface was treated with oxygen plasma for 5 mins, so that a layer of hydroxyl $(-\mathrm{OH})$ groups was formed. After that, the sensor was immersed in a $2 \%(\mathrm{v} / \mathrm{v})$ APTES anhydrous ethanol solution for 45 mins. For each APTES molecule, 3 oxyethyl groups and 1 amino group were provided. The oxyethyl group was combined with the hydroxyl groups. Free amino groups provided by glutaraldehyde (Glu) could bond to the aldehyde group. The chip was then immersed in a $2.5 \%(\mathrm{v} / \mathrm{v})$ Glu solution for an hour. Finally, a $100 \mu \mathrm{g} / \mathrm{ml}$ CEA antibody solution was dripped onto the nanowires surface and kept for $4 \mathrm{hrs}$. The amino groups in the antibody proteins were bound tightly to the aldehyde groups within glutaraldehyde.

\section{Microchannel formation}

A 4-inch silicon chip was made into a microchannel mold (150 $\mu \mathrm{m}$ in height) by coating lithography and deep silicon etching technology. PDMS prepolymer and polymer were thoroughly mixed at a mass ratio of 10:1, and the mixture was poured into a microchannel mold. Bubbles in the PDMS were removed by placing it into a vacuum tank. It was further incubated at $75{ }^{\circ} \mathrm{C}$ for 40 mins. After cooling, holes were punched in order to obtain the desired PDMS flow path. The microchannel was cleaned and a layer of hydroxy was applied to the surface with Plasma Cleaner. Finally, the antibody-modified nanodevices were used to reversibly seal the microchannel PDMS and were fixed with acrylic plates.

\section{Dialyzer connection}

The dialysis fibrosis tube in the miniature blood dialyzer was made by dialysis membrane with an aperture of 10,000 D. It was calculated according to the serum amount needed for dialysis. The serum amount of each dialysis was about $2 \mathrm{ml}$, whereas the total area of the dialysis membrane was $0.01 \mathrm{~m}^{2}$. The dialysis-completed fiber tubes were then placed in the miniature dialyzer housing. The length and diameter of the final dialyzer were $8.5 \mathrm{~cm}$ and $2 \mathrm{~cm}$, respectively (Figure 5). A pressure regulator was installed in the dialysis unit to keep the serum volume constant before and after dialysis. Lastly, the DialysisSilicon Nanowire Field Effect Transistor (Dialysis-SiNWFET) was formed by connecting the whole dialyzer to the microchannel system.

\section{Detection}

All detections were performed with an Agilent B1500A Semiconductor Device Analyzer (Agilent Technologies Inc., Santa Clara, CA, USA). Four probes were connected to the four electrodes of the nanodevices with the voltage set to $2 \mathrm{~V}$ (source), $0 \mathrm{~V}$ (drain), $2 \mathrm{~V}$ (top gate), and $0.8 \mathrm{~V}$ (back gate). A peristaltic pump was used as the power device for the whole microchannel system, and the flux was about $80 \mu \mathrm{l} / \mathrm{min}$. In order to ensure stable current at the time of detection, 120-180 seconds of solution passing time were allowed. Detections were repeated 3 times to ensure the reliability of the results.

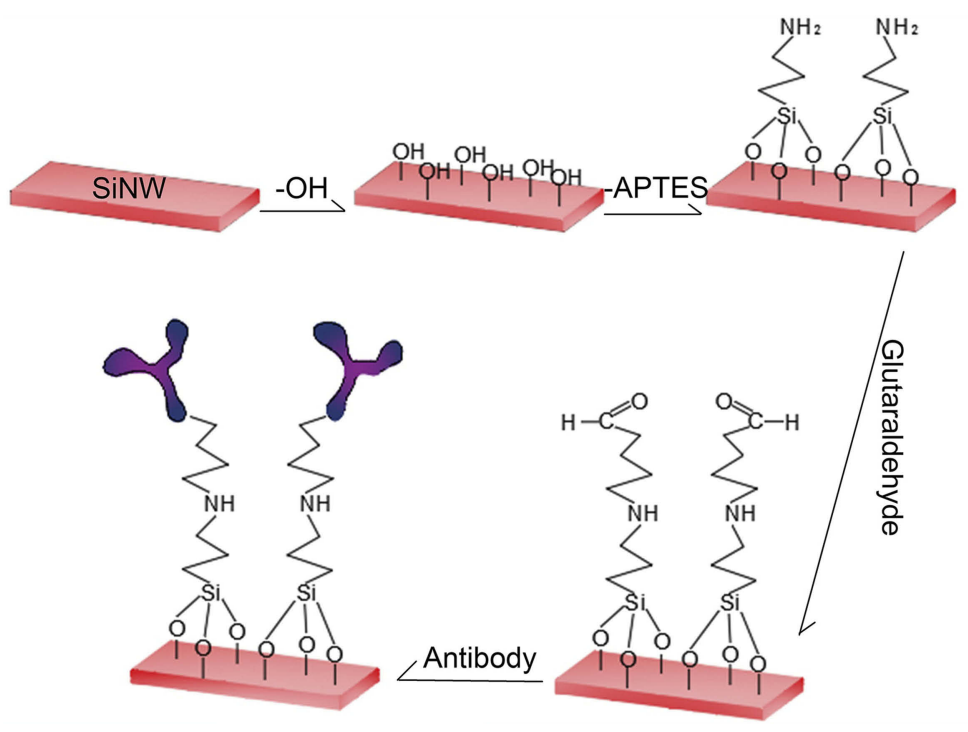

Figure 4 The process of functional modification of silicon nanowires. 


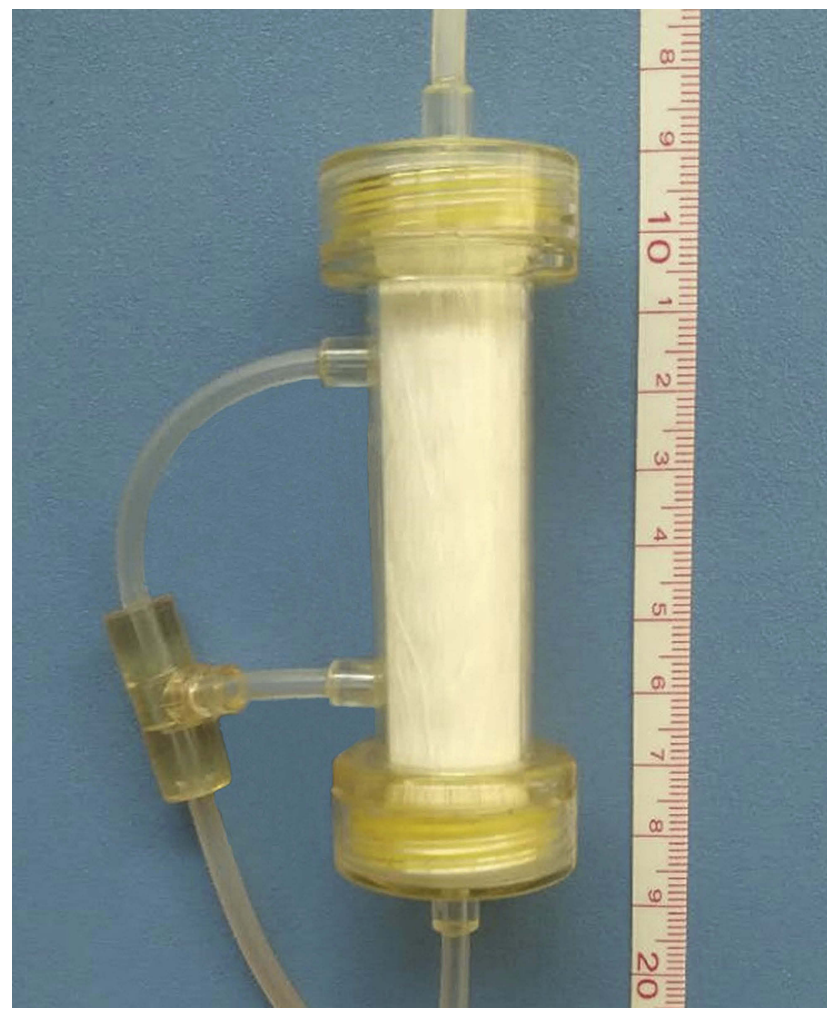

Figure $\mathbf{5}$ The image of the miniature blood dialyzer.

\section{Results and discussion \\ Nanodevice structure and performance}

The width of nanowire is $500 \mathrm{~nm}$ and the height is $30 \mathrm{~nm}$ as shown in the scanning electron microscope (SEM) image (Figure 6A). Figure 6B shows the structure image of each electrode of the device. The SiNW connected the source and the drain electrode. It was coated with an oxide layer with a thickness of $50 \mathrm{~nm}$ with the top gate located on the oxide layer. The back gate is plated on the back substrate such that the double grid electrode can form a ring around the silicon nanowire for better control. The performance of the device was tested as shown in the transfer curve (Figure 6C). When the source drain voltage $(\mathrm{Vds}=3 \mathrm{~V})$ and back gate voltage $\left(\mathrm{V}_{\text {back }}=0.8 \mathrm{~V}\right)$ were fixed, the output current (Ids) increased with the top gate voltage $\left(\mathrm{V}_{\text {top }}\right)$. Figure $6 \mathrm{D}$ shows the output curve. When the back gate voltage $\left(\mathrm{V}_{\text {back }}=0.8 \mathrm{~V}\right)$ was fixed, Ids changed relative to $\mathrm{Vds}$ after a different gate voltage was applied. Ids and conductance increased with $\mathrm{V}_{\text {top }}$ in the same Vds. This illustrated that the gate voltage had an excellent regulation effect on the silicon nanowire conductance, and the performance of the device met the detection requirements.

\section{Functional results}

The traditional APTES-Glu chemical chain modification method was validated with atomic force microscopy (AFM) and fluorescence microscopy. AFM images of the modified silicon nanowire showed spherical particles on the devices, in which particle size was consistent with protein size (Figure 7A). Since fluorescence proteins were used to replace the tumor marker antibody, a layer of green fluorescent proteins were successfully attached to the silicon nanowire (Figure 7B). A tumor marker antibody was successfully fixed onto the silicon nanowire using the current modification method that was the basis for the application of semiconductor material detection.

\section{Serum dialysis results}

The essence of the dialysis desalination of miniature blood dialyzer is that the dialysate (deionized water) continuously removes salt ions from the serum through a dialysis membrane. The dialysis membrane's pores act as a filter. Salt ions, creatinine, urea, and uric acid may cross due to the concentration gradient until the molecules equally distribute across the membrane. Proteins remained in the serum because their molecules were larger than the membrane's pores; however, smaller molecules, such as salt ions, creatinine, urea, and uric acid, were continuously removed from the serum. While water molecules can pass through the dialysis membrane, serum volume could not be controlled by a single dialysis membrane. And the detection outcome cannot indicate the initial concentration of serum tumor markers. A pressure control device was then used to detect and regulate the volume, flow, and pressure of dialysis fluid in the machine. The distribution of water molecules on both sides of the dialysis membrane was regulated by the pressure of dialysis fluid to achieve the consistency of serum volume before and after dialysis. As shown in the Table 1, the serum contents after dialysis were tested. The ionic strength after dialysis was about $3.0 \mathrm{mM}$, which was $2 \%$ of the original serum. Creatinine, urea, and uric acid were all removed, whereas serum albumin, target tumor markers, and serum volume remained nearly unchanged. We have concluded that the miniature blood dialyzer can remove some interfering detection factors while maintaining the in situ detection effect of serum tumor markers. Therefore, this method can effectively reduce the Debye screening effect of silicon nanowire biosensors in order to detect biological molecules. 


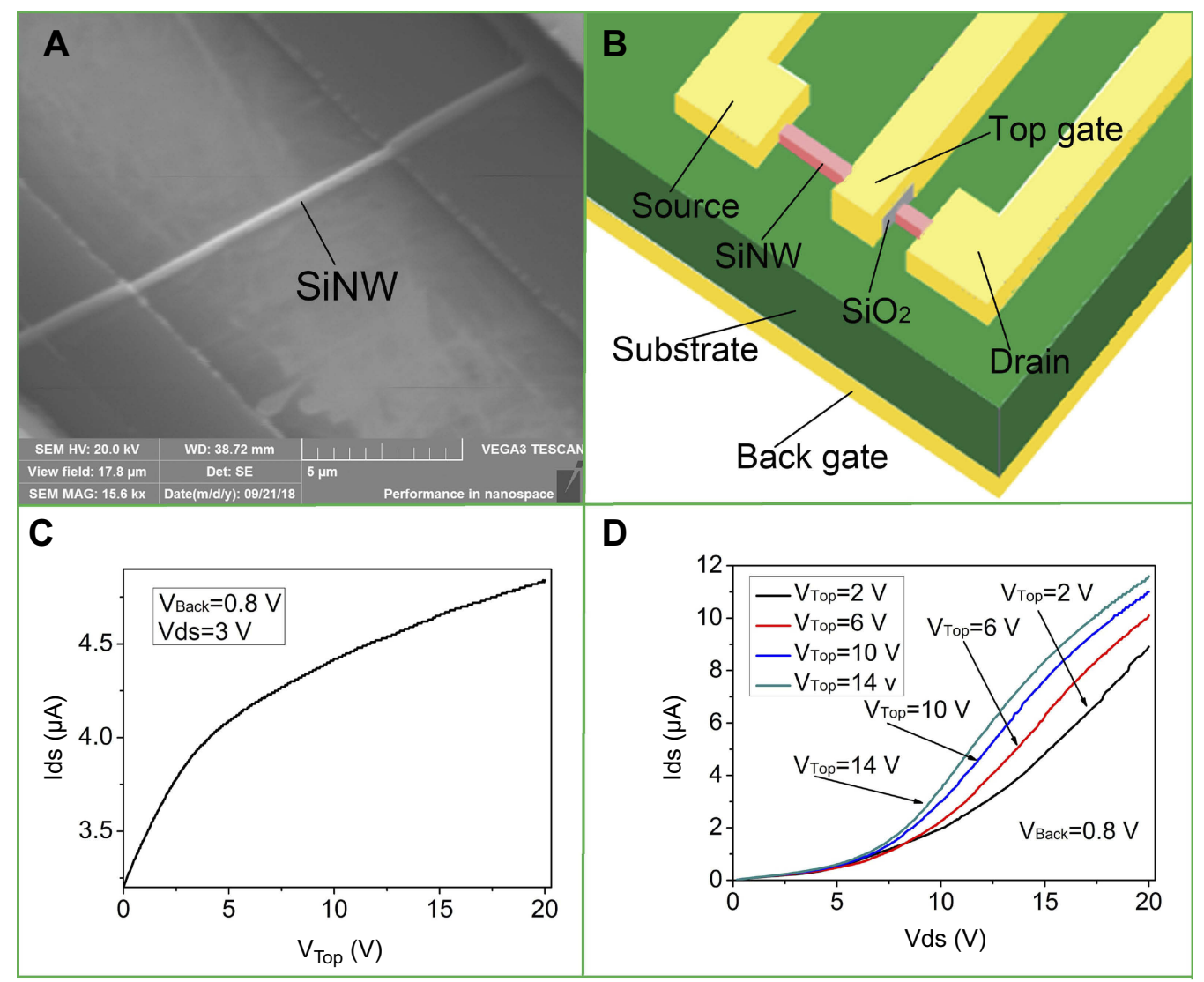

Figure 6 The structure and properties of silicon nanowire devices. (A) An SEM image of SiNW. (B) A schematic of the distribution of the electrodes in a silicon nanowire device. (C) The transfer curve image. (D) The output curve image.

Abbreviation: SiNW, silicon nanowire.

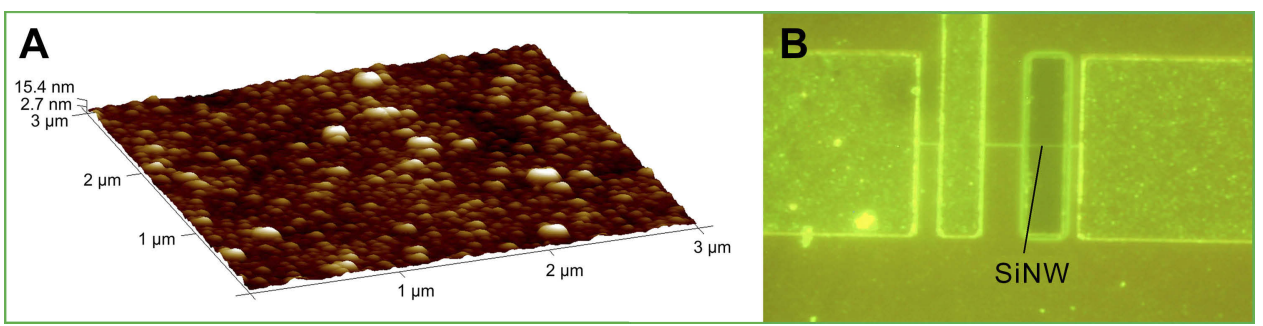

Figure 7 The results of functional silicon nanowire modification. (A) The AFM image of functioned SiNW. (B) The results after modification of the fluorescent protein. Abbreviation: SiNW, silicon nanowire.

\section{Detection results of tumor markers}

The detection capability was evaluated with tumor markers CEA and AFP. CEA is a proteoglycan polymer with a molecular weight of about 150-200 kDa. The serum concentration in healthy subjects is less than $5 \mathrm{ng} / \mathrm{ml}$. Elevated CEA is a common indicator in the clinical detection of many cancers, including colorectal cancer, pancreatic cancer, gastric cancer, breast cancer, medullary thyroid cancer, liver cancer, lung cancer, ovarian cancer, and urinary cancer. AFP is a proteoglycan polymer with a molecular weight of about 69 $\mathrm{kDa}$ and a serum concentration of less than $10 \mathrm{ng} / \mathrm{ml}$ in a healthy subject. At present, AFP is mainly used as a marker of primary liver cancer.

Figure $8 \mathrm{~A}-\mathrm{C}$ showed the test results of a standard solution, which were made with $0.02 \times$ PBS and pure antigens. SiNWFET biosensors modified with different antibodies can detect corresponding tumor markers at different concentrations measuring the current. The detected current increased with marker 
Table I Compositional variation in the serum before and after dialysis

\begin{tabular}{|l|l|l|}
\hline & $\begin{array}{l}\text { Before } \\
\text { dialysis }\end{array}$ & After dialysis \\
\hline $\mathrm{K}^{+}$ & $4.11 \mathrm{mmol} / \mathrm{L}$ & $0.150 \mathrm{mmol} / \mathrm{L}$ \\
$\mathrm{Na}^{+}$ & $139.4 \mathrm{mmol} / \mathrm{L}$ & $3.762 \mathrm{mmol} / \mathrm{L}$ \\
$\mathrm{Cl}^{-}$ & $106.9 \mathrm{mmol} / \mathrm{L}$ & $0.0043 \mathrm{mmol} / \mathrm{L}$ \\
$\mathrm{Ca}^{2+}$ & $2.29 \mathrm{mmol} / \mathrm{L}$ & $0.0834 \mathrm{mmol} / \mathrm{L}$ \\
Creatinine & $57.2 \mu \mathrm{mol} / \mathrm{L}$ & $\begin{array}{l}\text { Less than detection limit } \\
(4.1 \mu \mathrm{mol} / \mathrm{L})\end{array}$ \\
Urea & $3.1 \mathrm{mmol} / \mathrm{L}$ & $\begin{array}{l}\text { Less than detection limit } \\
(0.1 \mathrm{mmol} / \mathrm{L})\end{array}$ \\
Uric ucid & $231.7 \mu \mathrm{mol} / \mathrm{L}$ & $\begin{array}{l}\text { Less than detection limit } \\
(2.4 \mu \mathrm{mol} / \mathrm{L})\end{array}$ \\
Serum albumin & $44.9 \mathrm{~g} / \mathrm{L}$ & $43.6 \mathrm{~g} / \mathrm{L}$ \\
PH & 7.4 & 7.4 \\
The volume of & $30 \mathrm{ml}$ & $30 \mathrm{ml}$ \\
serum & & $2.49 \mathrm{ng} / \mathrm{ml}$ \\
AFP & $2.49 \mathrm{ng} / \mathrm{ml}$ & $2.46 \mathrm{ng} / \mathrm{ml}$ \\
CEA & $2.46 \mathrm{ng} / \mathrm{ml}$ &
\end{tabular}

concentration. As shown in Figure 8A-C, the SiNW-FET biosensor modified with different antibodies had detection specificity, which was related to the antigen-antibody specific reaction; whereas, biosensors without modified antibodies did not respond to tumor markers or proteins.
Figure 8D-F shows the detection results for serum tumor markers. Serum 1 was the normal serum with a CEA concentration of $2.46 \mathrm{ng} / \mathrm{ml}$ and an AFP concentration of $2.29 \mathrm{ng} / \mathrm{ml}$. And serum 2 was the serum of liver cancer patients, with a CEA concentration of $6.54 \mathrm{ng} / \mathrm{ml}$ and an AFP concentration of $17.44 \mathrm{ng} / \mathrm{ml}$. It was shown that serum after dialysis desalination altered the current of the biosensor, while the original serum without any treatment did not alter the response of the biosensor. Figure 9A and B showed the relationship between concentration and current after detection by different serum tumor markers.

\section{Conclusion}

Serum tumor markers were successfully detected by a silicon nanowire biosensor controlled by a double gate. This proved the feasibility of semiconductor materials in biological detection. The combined application with miniature blood dialyzer overcame the Debye screening effect, broadening the silicon nanowire biosensor's application range for biological detection and allowing detection of biological molecules at a low concentration.

\section{Acknowledgments}

This study was supported by National Science Foundation (81371683 and 81702592), Wuxi Medical Emphasis
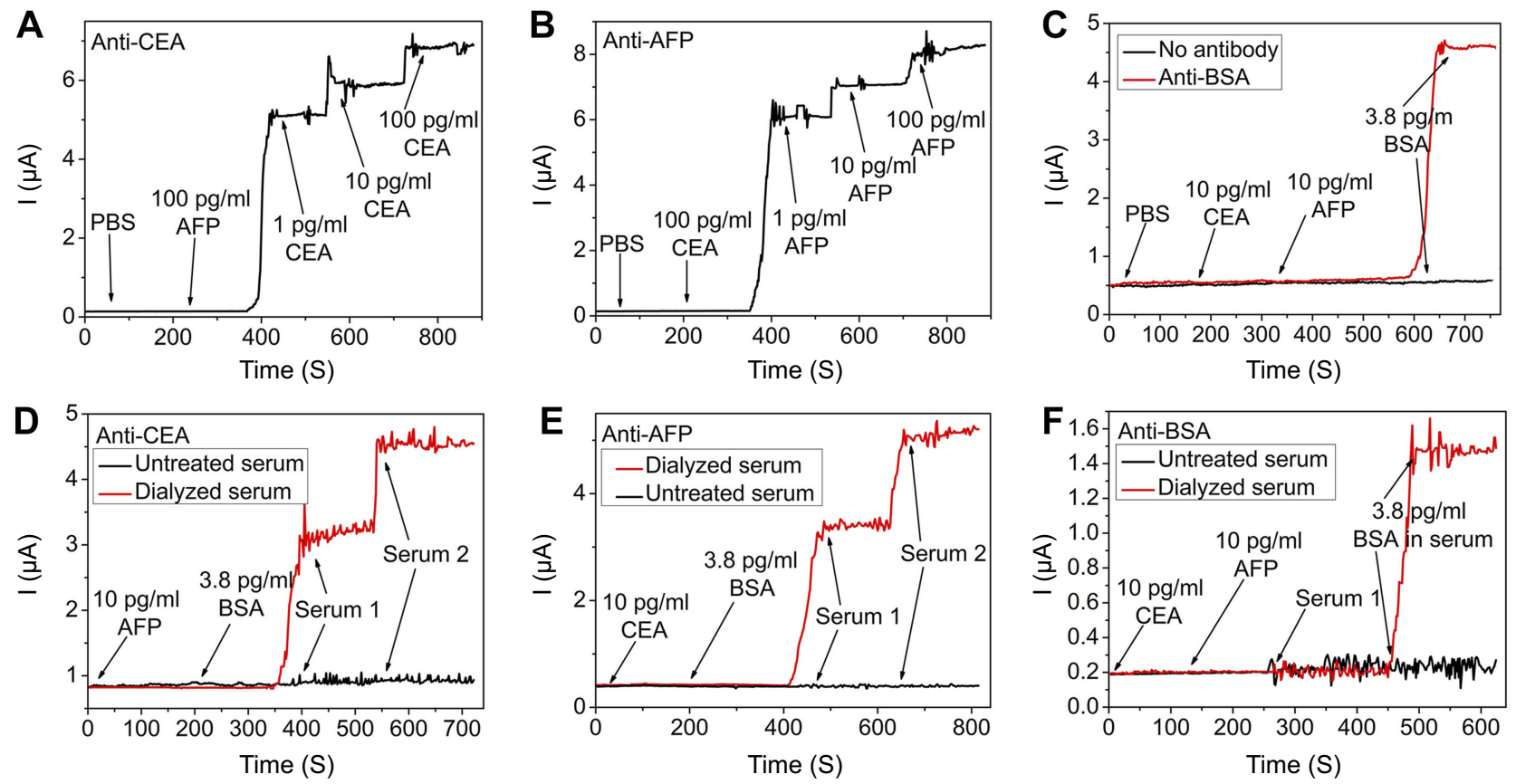

Figure 8 The detection results on Dialysis-SiNW-FET. (A) The standard solution detection results of anti-CEA SiNW-FET. (B) The standard solution detection results of anti-AFP SiNW-FET. (C) The standard solution detection results of no antibody SiNW-FET and anti-BSA SiNW-FET. (D) The serum detection results of anti-CEA SiNW-FET. (E) The serum detection results of anti-AFP SiNW-FET. (F) The serum detection results of anti-BSA SiNW-FET.

Abbreviation: SiNW-FET, silicon nanowire field effect transistor. 
A

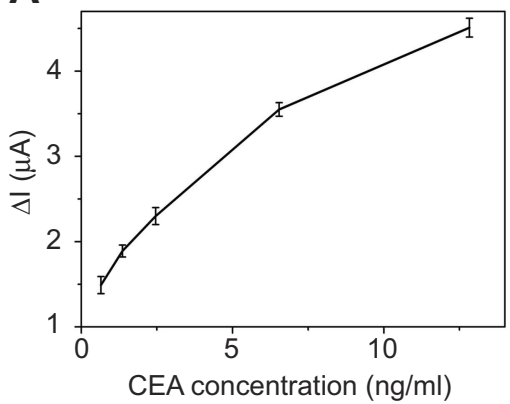

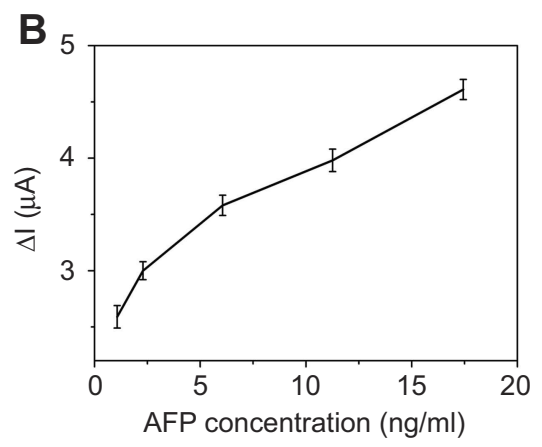

Figure 9 The human serum detection results of different tumor markers. (A) The human serum detection results with different CEA concentrations. (B) The human serum detection results with different AFP concentrations.

Disciplines Funding (syxzdxk-pwk), Wuxi Science and Technology Development Plan (CZE02H1701), Clinical Medicine Project of Jiangsu Province (BL2014023) and National Sciences Foundation of Jiangsu Province (BK20160198).

\section{Disclosure}

The authors report no conflicts of interest in this work.

\section{References}

1. Catalano PW, Martin EJ, Ellison C, Carey LC. Reasonable surgical treatment for tumors of the liver associated with the use of oral contraceptives. Surg Gynecol Obstet. 1979;148:759-763.

2. Morse MA, Hanks BA, Suhocki P, et al. Improved time to progression for transarterial chemoembolization compared with transarterial embolization for patients with unresectable hepatocellular carcinoma. Clin Colorectal Cancer. 2012;11:185-190. doi:10.1016/ j.clcc.2011.11.003

3. Lee JG, Kang CM, Park JS, et al. The actual five-year survival rate of hepatocellular carcinoma patients after curative resection. Yonsei Med J. 2006;47:105-112. doi:10.3349/ymj.2006.47.1.105

4. Hassan AS, Naicker M, Yusof KH, Ishak WZW. Prognostic factors and the role of adjuvant chemotherapy in post-curative surgery for dukes B and C colon cancers and survival outcomes: a Malaysian experience. Asian Pac J Cancer Prev. 2015;16:2237-2243.

5. Cao D-X, Wang Q-G, Ji Y, et al. Diagnostic methods for initial evaluation of primary gastrointestinal stromal tumors. Saudi Med J. 2010;31:262-269.

6. Giardina MG, Matarazzo M, Morante $R$, et al. Serum alpha-L-fucosidase activity and early detection of hepatocellular carcinoma: a prospective study of patients with cirrhosis. Cancer Am Cancer Soc. 1998;83:2468-2474.

7. Valzasina B, Guiducci C, Dislich $\mathrm{H}$, et al. Triggering of OX40 (CD134) on $\mathrm{CD} 4(+) \mathrm{CD} 25+\mathrm{T}$ cells blocks their inhibitory activity: a novel regulatory role for OX40 and its comparison with GITR. Blood. 2005;105:2845-2851. doi:10.1182/blood-2004-07-2959

8. Cujic D, Golubovic S, Bojic-Trbojevic Z, et al. Differential diagnosis of liver diseases using serum biomarkers. J BUON. 2010;15:141-146.

9. Nakanishi H, Kodera Y, Yamamura Y, Tatematsu M. [Rapid quantitative detection of free cancer cells in the peritoneal cavity of gastric cancer patients with real-time RT-PCR, and its prognostic significance]. Gan To Kagaku Ryoho. 2001;28:784-788.
10. Ito S, Nakanishi H, Hirai T, et al. Quantitative detection of CEA expressing free tumor cells in the peripheral blood of colorectal cancer patients during surgery with real-time RT-PCR on a LightCycler. Cancer Lett. 2002;183:195-203.

11. Li B-R, Chen C-C, Kumar UR, Chen Y-T. Advances in nanowire transistors for biological analysis and cellular investigation. Analyst. 2014;139:1589-1608. doi:10.1039/c3an01861j

12. Cui Y, Wei Q, Park H, Lieber CM. Nanowire nanosensors for highly sensitive and selective detection of biological and chemical species. Science. 2001;293:1289-1292. doi:10.1126/science.1062711

13. Stern E, Klemic JF, Routenberg DA, et al. Label-free immunodetection with CMOS-compatible semiconducting nanowires. Nature. 2007;445:519-522. doi:10.1038/nature05498

14. Zheng G, Patolsky F, Cui Y, et al. Multiplexed electrical detection of cancer markers with nanowire sensor arrays. Nat Biotechnol. 2005;23:1294-1301. doi:10.1038/nbt1138

15. Evoy S, DiLello N, Deshpande V, et al. Dielectrophoretic assembly and integration of nanowire devices with functional CMOS operating circuitry. Microelectron Eng. 2004;75:31-42. doi:10.1016/j. mee.2003.09.010

16. Cheng MM, Cuda G, Bunimovich YL, et al. Nanotechnologies for biomolecular detection and medical diagnostics. Curr Opin Chem Biol. 2006;10:11-19. doi:10.1016/j.cbpa.2006.01.006

17. Wang WU, Chen C, Lin K-H, et al. Label-free detection of small-moleculeprotein interactions by using nanowire nanosensors. Proc Natl Acad Sci U S A. 2005;102:3208-3212. doi:10.1073/pnas.0406368102

18. Bao Z, Sun J, Zhao X, et al. Top-down nanofabrication of silicon nanoribbon field effect transistor (Si-NR FET) for carcinoembryonic antigen detection. Int $J$ Nanomedicine. 2017;12:4623-4631. doi:10.2147/IJN.S135985

19. Gao A, Lu N, Dai P, et al. Direct ultrasensitive electrical detection of prostate cancer biomarkers with CMOS-compatible n- and p-type silicon nanowire sensor arrays. Nanoscale. 2014;6:13036-13042. doi:10.1039/c4nr03210a

20. Stern E, Wagner R, Sigworth FJ, et al. Importance of the Debye screening length on nanowire field effect transistor sensors. Nano Lett. 2007;7:3405-3409. doi:10.1021/n1071792z

21. Gao N, Zhou W, Jiang X, et al. General strategy for biodetection in high ionic strength solutions using transistor-based nanoelectronic sensors. Nano Lett. 2015;15:2143-2148. doi:10.1021/acs. nanolett.5b00133

22. Zhang G-J, Ning Y. Silicon nanowire biosensor and its applications in disease diagnostics: a review. Anal Chim Acta. 2012;749:1-15. doi:10.1016/j.aca.2012.08.035

23. Kim A, Ah CS, Park CW, et al. Direct label-free electrical immunodetection in human serum using a flow-through-apparatus approach with integrated field-effect transistors. Biosens Bioelectron. 2010;25:1767-1773. doi:10.1016/j.bios.2009.12.026 
24. Lee J-O, So H-M, Jeon E-K, et al. Aptamers as molecular recognition elements for electrical nanobiosensors. Anal Bioanal Chem. 2008;390:1023-1032. doi:10.1007/s00216-007-1643-y

25. Gao XP, Zheng G, Lieber CM. Subthreshold regime has the optimal sensitivity for nanowire FET biosensors. Nano Lett. 2010;10:547-552. doi:10.1021/n19034219

26. Korotkova N, Yang Y, Le Trong I, et al. Binding of Dr adhesins of Escherichia coli to carcinoembryonic antigen triggers receptor dissociation. Mol Microbiol. 2008;67:420-434. doi:10.1111/j.13652958.2007.06054.x

27. Elnathan R, Kwiat M, Pevzner A, et al. Biorecognition layer engineering: overcoming screening limitations of nanowire-based FET devices. Nano Lett. 2012;12:5245-5254. doi:10.1021/nl302434w

28. Krivitsky V, Hsiung L-C, Lichtenstein A, et al. Si nanowires forest-based on-chip biomolecular filtering, separation and preconcentration devices: nanowires do it all. Nano Lett. 2012;12:4748-4756. doi: $10.1021 / \mathrm{nl} 3021889$
29. Gao N, Gao T, Yang X, et al. Specific detection of biomolecules in physiological solutions using graphene transistor biosensors. Proc Natl Acad Sci US A. 2016;113:14633-14638. doi:10.1073/pnas.1625010114

30. Ronco C, Clark WR. Haemodialysis membranes. Nat Rev Nephrol. 2018;14:394-410. doi:10.1038/s41581-018-0002-x

31. Polaschegg H-D. Hemodialysis machine technology: a global overview. Expert Rev Med Devices. 2010;7:793-810. doi:10.1586/ erd.10.54

32. Himmelfarb J, Ikizler TA. Hemodialysis. $N$ Engl J Med. 2010;363 (19):1833-1845. doi:10.1056/NEJMra0902710

33. Eknoyan G, Beck GJ, Cheung AK, et al. Effect of dialysis dose and membrane flux in maintenance hemodialysis. $N$ Engl J Med. 2002;347:2010-2019. doi:10.1056/NEJMoa021583

\section{Publish your work in this journal}

The International Journal of Nanomedicine is an international, peerreviewed journal focusing on the application of nanotechnology in diagnostics, therapeutics, and drug delivery systems throughout the biomedical field. This journal is indexed on PubMed Central, MedLine, CAS, SciSearch ${ }^{\circledR}$, Current Contents ${ }^{\circledR} /$ Clinical Medicine,
Journal Citation Reports/Science Edition, EMBase, Scopus and the Elsevier Bibliographic databases. The manuscript management system is completely online and includes a very quick and fair peer-review system, which is all easy to use. Visit http://www.dovepress.com/ testimonials.php to read real quotes from published authors. 